\title{
BMJ Open Dietary intake in young adults born small or appropriate for gestational age: data from the Haguenau cohort
}

\author{
Joane Matta, ${ }^{1}$ Claire Carette ${ }^{2}$ Claire Levy Marchal, ${ }^{3}$ Julien Bertrand,,${ }^{4,5}$ \\ Mélanie Pétéra, ${ }^{4,5}$ Marie Zins, ${ }^{1,6}$ Estelle Pujos-Guillot, ${ }^{4,5}$ Blandine Comte, ${ }^{4,5}$ \\ Sébastien Czernichow ${ }^{1,2,6}$
}

To cite: Matta J, Carette C, Levy Marchal C, et al. Dietary intake in young adults born small or appropriate for gestational age: data from the Haguenau cohort. BMJ Open 2016;6: 012309 .

doi:10.1136/bmjopen-2016012309

- Prepublication history for this paper is available online. To view these files please visit the journal online (http://dx.doi.org/10.1136/ bmjopen-2016-012309).

Received 15 April 2016 Revised 16 May 2016 Accepted 24 May 2016

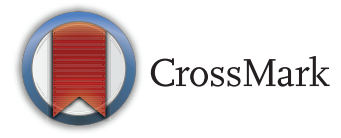

For numbered affiliations see end of article.

\section{Correspondence to}

Professor Sébastien

Czernichow;

sebastien.czernichow@aphp. $\mathrm{fr}$

\section{ABSTRACT}

Objectives: Compare the dietary intake of young adults born small for gestational age (SGA) versus those born appropriate for gestational age (AGA).

Design: Cross-sectional analysis.

Setting: Data at the 8-year follow-up Haguenau cohort (France). Data from 229 AGA-born adults and 172 SGA-born adults with available dietary information are presented.

Methods: Dietary intake was based on a food questionnaire including 19 items. The $\chi^{2}$ test was run to compare intake between SGA-born and AGA-born individuals. An a priori score was calculated based on the adherence to recommendations from the French Nutrition and Health Program and included 8 components with the lowest value indicating a lower adherence to recommendations. The score was then divided into quartiles. Relative risks and $95 \% \mathrm{Cls}$, controlling for age and sex in multivariate analysis, were calculated in order to determine the risk of belonging to the first versus the second to the fourth quartiles in SGA-born and AGA-born individuals.

Results: Intakes of SGA-born adults indicated that they consumed more meat, sugar and less fish than AGA-born individuals (all $p<0.05$ ). Multivariate analyses with adjustment for age and sex showed that the relative risk of belonging to the first quartile versus the other three quartiles did not disclose any significant difference in SGA-born versus AGA-born participants: $\mathrm{RR}=0.92(95 \% \mathrm{Cl} 0.65$ to 1.30$)$.

Conclusions: Aside from the differences found by univariate analyses, no significant differences were obtained in multivariate analyses. Findings suggest that parameters of fetal programming are more associated with the development of metabolic syndrome in adulthood rather than dietary patterns.

\section{INTRODUCTION}

Low birth weight and small for gestational age (SGA) have both been associated with later higher susceptibility for development of impaired metabolic phenotype such as obesity, hypertension and insulin resistance (IR), as

\section{Strengths and limitations of this study}

- Homogeneous population.

- High participation rate which reduces selection bias between appropriate for gestational age (AGA) and small for gestational age (SGA).

- First study to evaluate risk of dietary intake of adults born SGA versus those born AGA.

- First study to highlight the importance of comparing dietary intake of adults based on weight for gestational age.

- The food items in the questionnaire used are limited but still provide information on dietary intake.

- Small subgroup of the population and thus might have not had enough power to detect significant differences with regard to dietary intake.

well as type 2 diabetes in adulthood. This has been well documented in several studies pointing out the negative consequences of nutritional inadequacies during fetal and early life.

The mechanisms have not yet been fully elucidated and several hypotheses have been proposed, including the 'small baby syndrome' or 'the fetal origins' hypothesis proposed by Barker and colleagues, and considers that undernutrition during critical periods in utero, could programme the metabolic syndrome and diabetes risks in adulthood. ${ }^{1}$ Another hypothesis, proposed by Hales and colleagues, is the thrifty phenotype which states that the fetus adapts to the adverse intrauterine environment and diverts limited nutrients to essential organs such as the brain at the expense of other less important organs such as the pancreas. ${ }^{2}$ On the other hand, Neel $e t a \vec{l}^{3}$ suggested the thrifty genotype hypothesis which considers that genes which promote survival and growth of the fetus also promote development of IR in a favourable environment. Data from the Haguenau cohort show that people born SGA have a sixfold increase in metabolic 
syndrome at the age of 22 years compared with individuals born appropriate for gestational age (AGA). ${ }^{4}$ The impact of lifestyle factors such as dietary intake of adults born SGA are not yet clear in the literature; they could potentially affect the development of cardiovascular diseases and impaired metabolic factors. ${ }^{5}$ Some animal studies have shown that intrauterine exposure may affect food intake later in life and have suggested the prenatal programming effect of obesity when exposed to undernutrition. ${ }^{6}$ Moreover, results from the Dutch Famine Birth Cohort showed that prenatal exposure to famine and consequently lower birth weight and smallness at birth are associated with a preference for fatty foods and an atherogenic serum profile among adults. ${ }^{7}$ It has also been shown in data from the Haguenau cohort that in case of obesity, SGA-born adults are at higher risk of developing metabolically unhealthy obesity. ${ }^{8}$

To the best of our knowledge, there are no published data comparing dietary intakes of adults born either SGA or AGA. In this study, we hypothesise that since SGA individuals tend to exhibit more unfavourable metabolic outcomes in adulthood, they could also have a different dietary pattern than AGA individuals. Then the present objective was to describe the dietary intakes of SGA-born and AGA-born individuals in the French Haguenau cohort.

\section{MATERIALS AND METHODS Study population}

Data were drawn from the Haguenau cohort, a community-based cohort derived from a maternity registry of the metropolitan area of the city of Haguenau (France) that has the purpose of investigating the longterm consequences of being born SGA. ${ }^{9}$ Briefly, the registry included information about all pregnancies and deliveries occurring at the city maternity hospital from 1971 to 1985 with an $80 \%$ degree of completeness.

SGA and AGA individuals were all singleton births and born between 32 and 42 weeks of gestation. SGA were individuals born with body weight $<10$ th centile with respect to local standard growth curves. AGA individuals were born between the 25th and the 75th centiles for sex and gestational age and were selected as the next full-term singleton after the selection of an SGA individual. ${ }^{10}$ Data in the Haguenau cohort were drawn at two time points with a participation rate of $80.7 \%$ at the second visit. ${ }^{4}$ The first visit took place when singletons were on average 22 years of age, and participants who agreed to participate were 886 AGA individuals and 734 SGA. $^{4}$ Since dietary intake was only inquired at the first visit and on only 536 participants, we included data from those with complete data $(n=401$ aged in average of 22 years, figure 1$)$.

Measurement strategy: Details about measurements are available in the previous publication of Meas et al. ${ }^{10}$ Cross-sectional analyses are presented in this work.

Dietary intake was evaluated using a self-administered questionnaire including 19 components and information on alcohol, water, meat, fish, poultry, eggs, dairy products, bread and sweets consumption.

An a priori score for dietary intake was also calculated based on adherence to French nutritional recommendations. ${ }^{11}$ Food groups were defined using the 'Programme National Nutrition Sante' (PNNS) guidelines. ${ }^{12}$ From the questionnaire that was available in the study, eight components were obtained: (1) alcohol; (2) water, sweetened beverages, soda; (3) fish; (4) bread; (5) meat, eggs, fish; (6) milk, dairy products; (7) total fats; and (8) sugar, desserts. Scoring (table 1) was based on the PNNS guidelines. At least one point was attributed when the behaviour was in accordance with the recommendations. Individuals who failed to meet the recommendation but came close had intermediate points, depending on the PNNS criteria. A 0.5 point was deducted from those who had an intake of sugar and desserts more than or equal to four times per week. The total score has a maximal value of 8 , with higher values indicating a better adherence to the French nutritional recommendations. The scores were compared between AGA-born and SGA-born adults.

Metabolic variables: Data on fasting total and highdensity lipoprotein cholesterol, triglycerides, plasma glucose and insulin levels were available and details are included elsewhere. ${ }^{10}$

All participants gave written consent.

\section{Statistical analyses}

Descriptive statistics were performed to provide characteristics of the sample studied and are presented as means \pm SD or percentages by type of weight for gestational age. Data from a total of 401 individuals with the complete data set are presented as a function of type (AGA, SGA). A $\chi^{2}$ test of independence was performed to examine the difference in intake between SGA-born and AGA-born individuals. Multiple correspondence analyses were run in order to determine relationships between components of the Food Frequency Questionnaire in SGA and AGA individuals. The a priori score was divided into quartiles. The SAS Genmod procedure adjusting for age and sex was used to compare relative risk and $95 \%$ CIs of belonging to the first quartile versus the other three quartiles in SGA-born versus AGA-born individuals. All tests were twotailed and $\mathrm{p}<0.05$ was considered significant. All analyses were undertaken using SAS V.9.3 software (SAS, Cary, North Carolina, USA).

\section{RESULTS}

Participants of the SGA group had significantly lower height and weight at age 22, but no significant difference was observed with regard to body mass index (BMI; table 2). Metabolic outcomes did not differ between both groups in the subpopulation with available dietary data.

Table 3 presents the results of $\chi^{2}$ analyses which identified significant differences in the intake of meat, sugar 
Figure 1 Flow chart of small for gestational age (SGA) and appropriate for gestational age (AGA) participants and the ones with dietary data information included in the analyses.

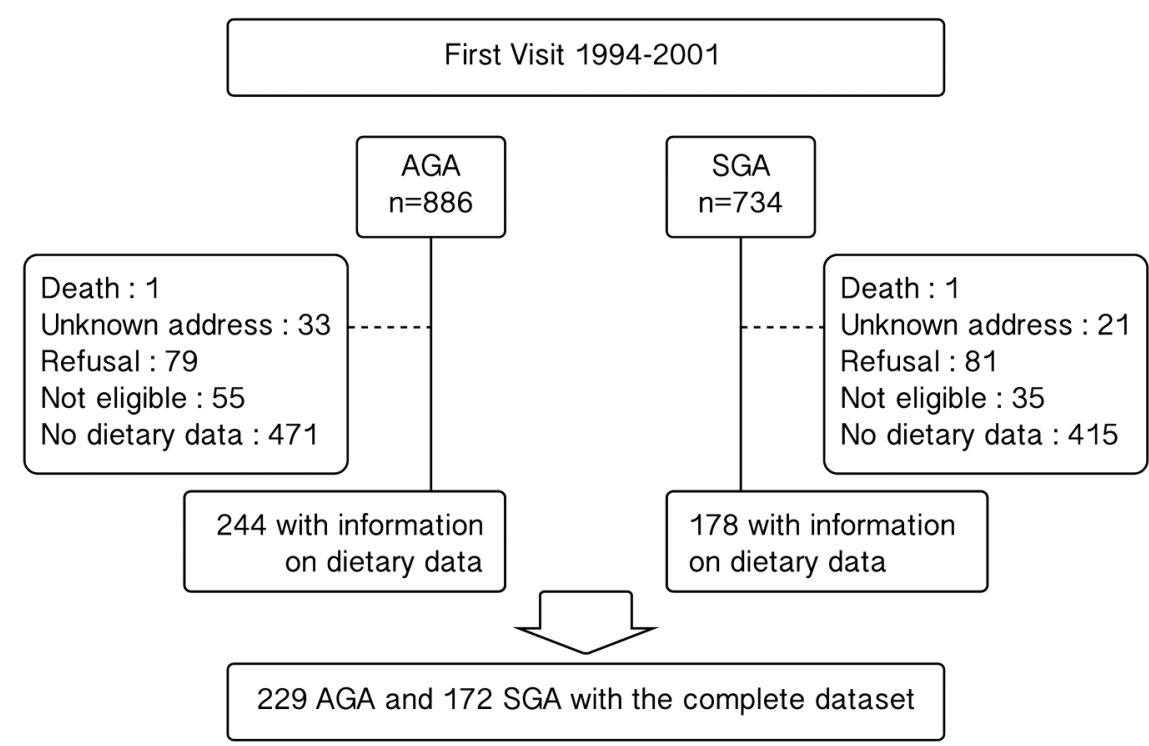

Table 1 Criteria for scoring calculation following the Programme National Nutrition Sante (PNNS) guidelines

\begin{tabular}{|c|c|c|c|}
\hline & Recommendation & Scoring criteria & Score \\
\hline \multirow[t]{5}{*}{ Alcohol } & $\leq 2$ glasses wine/day for women & Abstainers & 1 \\
\hline & $\leq 3$ glasses wine/day for men & $<1 / 2$ L/day for women & 0.5 \\
\hline & & More than $1 / 2 \mathrm{~L} /$ day for women & 0 \\
\hline & & $<1 / 2-1 \mathrm{~L} /$ day for men & 0.5 \\
\hline & & More than $1 \mathrm{~L} /$ day for men & 0 \\
\hline \multirow{4}{*}{$\begin{array}{l}\text { Water and sweetened } \\
\text { beverages or soda }\end{array}$} & Drink water as desired; limit sweetened & Water $<1 \mathrm{~L}$ and soda $\geq 1 / 2 \mathrm{~L} /$ day & 0 \\
\hline & beverages to $\leq 1$ glass/day & Water $\geq 1 \mathrm{~L}$ and soda $\geq 1 / 2 \mathrm{~L} /$ day & 0.5 \\
\hline & & Water $<1 \mathrm{~L}$ and soda $=0 /$ day & 0.75 \\
\hline & & Water $\geq 1 \mathrm{~L}$ and soda $=0 /$ day & 1 \\
\hline \multirow[t]{2}{*}{ Fish } & $\geq 2$ servings/week & Fish $<2$ servings/week & 0 \\
\hline & & Fish $\geq 2$ servings/week & 1 \\
\hline \multirow[t]{3}{*}{ Bread } & At each meal according to appetite & $<50 \mathrm{~g} /$ day & 0 \\
\hline & & $50-200 \mathrm{~g} /$ day & 1 \\
\hline & & $>200$ g/day & 0.5 \\
\hline \multirow{3}{*}{ Sugar and desserts } & Limit consumption & $\geq 4$ times/week & -0.5 \\
\hline & & $\begin{array}{l}<4 \text { times/week and more than } 1 \text { time/ } \\
\text { week }\end{array}$ & 0 \\
\hline & & 1 time or less/week & 1 \\
\hline \multirow[t]{3}{*}{ Total fats } & Limit consumption & 1 time or less/week & 1 \\
\hline & & 2-4 times/week & 0.5 \\
\hline & & More than 4 times/week & 0 \\
\hline \multirow[t]{3}{*}{ Meat, eggs and fish } & Servings/day & $\begin{array}{l}<100 \mathrm{~g} \text { of meat/day and }<4 \text { eggs/week } \\
\text { and }<2 \text { servings fish/week }\end{array}$ & 0.5 \\
\hline & & $\begin{array}{l}\text { Meat between } 100 \text { and } 200 \mathrm{~g} / \text { day and } \\
\text { eggs } 4-7 / \text { week and fish } 2-4 \text { servings/ } \\
\text { week }\end{array}$ & 1 \\
\hline & & $\begin{array}{l}\text { Meat }>200 \mathrm{~g} / \text { day and eggs }>8 / \text { week and } \\
\text { fish } \geq 4 \text { servings/week }\end{array}$ & 0 \\
\hline \multirow[t]{3}{*}{ Dairy products } & 3 servings/day & $\begin{array}{l}\text { Yogurt portion }<1 / \text { week and }<1 / \text { day dairy } \\
\text { product and }<1 \text { portion of cheese/day }\end{array}$ & 0 \\
\hline & & $\begin{array}{l}2-4 / \text { week yogurt portion and } 1-2 \text { dairy } \\
\text { product/day and } 2-3 \text { portions of cheese/ } \\
\text { day }\end{array}$ & 1 \\
\hline & & $\begin{array}{l}>4 \text { yogurt portion/week and }>2 \text { dairy } \\
\text { product/day and }>3 \text { cheese portions/day }\end{array}$ & 0.5 \\
\hline Total score & & & $\begin{array}{l}\text { Minimum }=0 \\
\text { Maximum }=8\end{array}$ \\
\hline
\end{tabular}


Table 2 Sample characteristics at baseline

\begin{tabular}{|c|c|c|c|}
\hline Variables & AGA $(n=229)$ & SGA $(n=172)$ & p Value \\
\hline Age, years & $22.0 \pm 4.5$ & $22.2 \pm 4.6$ & 0.75 \\
\hline Male, per cent & 44.1 & 43.6 & 0.92 \\
\hline Weight, kg & $71.4 \pm 16.1$ & $66.0 \pm 16.4$ & 0.001 \\
\hline Height, $\mathrm{cm}$ & $170.9 \pm 8.0$ & $167.6 \pm 8.7$ & $<0.001$ \\
\hline BMI, height $/ \mathrm{m}^{2}$ & $24.3 \pm 4.6$ & $23.4 \pm 5.2$ & 0.06 \\
\hline Waist circumference, $\mathrm{cm}$ & $78.0 \pm 10.7$ & $75.9 \pm 12.6$ & 0.08 \\
\hline Diastolic blood pressure, $\mathrm{mm} \mathrm{Hg}$ & $61.5 \pm 10.2$ & $61.6 \pm 10.1$ & 0.95 \\
\hline Total cholesterol, mM & $4.4 \pm 0.8$ & $4.5 \pm 0.9$ & 0.62 \\
\hline HDL-cholesterol, mM & $1.5 \pm 0.3$ & $1.4 \pm 0.3$ & 0.49 \\
\hline Triglycerides, mM & $1.0 \pm 0.4$ & $1.1 \pm 0.5$ & 0.07 \\
\hline Fasting glucose, $\mathrm{g} / \mathrm{L}$ & $0.8 \pm 0.06$ & $0.8 \pm 0.07$ & 0.89 \\
\hline
\end{tabular}

and fish $(p<0.05)$, with SGA-born adults consuming more meat and sugar and less fish than AGA-born individuals. No other significant differences were observed.

Results presented in table 4 show the univariate and multivariate relative risks for quartile 1 of dietary score versus quartiles 2-4 in SGA versus AGA individuals. The relative risk of belonging to the first quartile versus the other three quartiles did not disclose any significant difference between SGA-born and AGA-born participants: $\mathrm{RR}=0.92(95 \%$ CI 0.65 to 1.30 ; table 4$)$.

Multiple correspondence analyses did not reveal additional significant differences in dietary patterns between SGA and AGA individuals (results not shown). Sensitivity analyses comparing age, sex and BMI between individuals with and without available dietary data did not disclose any significant differences.

\section{DISCUSSION}

In this study, we examined the differences in dietary intakes of young adults in their early 20s, born either SGA or AGA. We found that SGA-born adults were less likely to consume fish and more likely to eat meat and sweets when compared with their AGA-born counterparts. Fish consumption has been strongly associated with a lesser risk of cardiovascular diseases. ${ }^{13}$ Our results suggest that small weight for gestational age might influence food choice and therefore health outcomes in adult years. We also found a difference in desserts intake but not in that of bread.

Data from a Brazilian birth cohort $^{14}$ showed that women who were born with intrauterine growth restriction had a spontaneous preference for carbohydrate intake instead of proteins and thus had a higher carbohydrate-to-protein ratio, which we find in our study by a higher dessert intake. Moreover, it has been shown that intrauterine growth restriction is strongly correlated with the hedonic response to a sweet solution on the first day of life of preterm infants. ${ }^{15}$ This might be related to the programming that occurs in utero with the preference to palatable foods in intrauterine growth restriction and preterm infants. ${ }^{16}$ No significant differences were observed here in either fat or alcohol intake.

Results from the Dutch famine cohort have shown that gestational famine exposure was associated with a preference for higher fat intake ${ }^{7}$ as well as another study by Stein $e t a l^{17}$ which showed that gestational famine was associated with higher energy intake and higher fat density compared with sibling controls. Difference in results might be related to the population studied. Our sample is composed of SGA young adults who have not experienced in childhood the same programming of infants exposed to gestational famine.

Besides, the differences in results may be also based on countries-ethnic own preferences.

However, when we calculated the score based on PNNS guidelines, we did not find a significant difference in the risk of belonging to the lower quartile of the dietary score between groups, the lower quartile indicating lesser adherence to nutritional recommendations. Multiple correspondence analyses did not reveal additional significant differences regarding dietary score between AGA and SGA individuals. Our findings by multivariate analyses, controlling for age and sex, suggest that factors that occur in utero and affect fetal programming have a higher impact on the risk of metabolic syndrome (as previously published ${ }^{10}$ ) rather than dietary intake in adulthood. However, Shultis et $a l^{18}$ have shown that there was no association between low birth weight and macronutrient intake in childhood after correction for gestational age and social variables, except for saturated fat intake.

The sample size with available dietary measurements was small compared with the whole sample, though sensitivity analyses did not disclose any significant differences between the two groups with regard to age, sex and BMI.

We have used a dietary questionnaire that included only 19 items, so a lack of precision in collected food consumption might lead to bias and underestimation of 
Table 3 Comparison of proportions of consumption in SGA-born versus AGA-born individuals

\begin{tabular}{|c|c|c|c|}
\hline Variables & AGA (\%) & SGA (\%) & p Value \\
\hline Alcoholic cocktails & & & 0.11 \\
\hline Yes & 35.4 & 27.9 & \\
\hline No & 64.6 & 72.1 & \\
\hline Wine & & & 0.90 \\
\hline No & 89.1 & 89.5 & \\
\hline$<1 / 2$ L/day & 10.9 & 10.5 & \\
\hline Beer & & & 0.53 \\
\hline No & 79.3 & 80.8 & \\
\hline$<1 / 2$ L/day & 16.7 & 14 & \\
\hline >1/2 L/day & 3.9 & 5.3 & \\
\hline Water & & & 0.56 \\
\hline No & 2.6 & 3.5 & \\
\hline$<1 / 2$ L/day & 11.4 & 13.4 & \\
\hline $1 / 2$ to 2 L/day & 78.2 & 77.9 & \\
\hline$>2 \mathrm{~L}$ & 7.9 & 5.2 & \\
\hline Non-alcoholic drinks & & & 0.28 \\
\hline No & 16.6 & 10.5 & \\
\hline$<1 / 2$ to $1 \mathrm{~L}$ & 74.3 & 82 & \\
\hline$>1$ to $3 \mathrm{~L}$ & 9.2 & 7.6 & \\
\hline Meat & & & 0.03 \\
\hline 100 g/day & 36.2 & 40.1 & \\
\hline 100 to $200 \mathrm{~g} /$ day & 61.1 & 52.3 & \\
\hline$>200$ g/day & 2.6 & 7.6 & \\
\hline Eggs & & & 0.58 \\
\hline$<4 /$ week & 87.3 & 89.5 & \\
\hline 4 to $7 /$ week & 12.2 & 10.5 & \\
\hline$\geq 8 /$ week & 0.4 & 0 & \\
\hline Fish & & & 0.04 \\
\hline$<2$ portions/week & 83.8 & 90.7 & \\
\hline 2 to 4 portions/week & 16.2 & 9.3 & \\
\hline Processed meat & & & 0.11 \\
\hline$\leq 1$ time/week & 34.6 & 36.5 & \\
\hline 2 to 4 times/week & 52.2 & 48.0 & \\
\hline$>4$ times/week & 13.2 & 15.2 & \\
\hline Fried products & & & 0.53 \\
\hline 1 time/week & 63.2 & 66.3 & \\
\hline$\geq 2$ times/week & 36.9 & 33.7 & \\
\hline Butter & & & 0.52 \\
\hline$\leq 1$ time/day & 64.3 & 69.6 & \\
\hline$\geq 2$ times/day & 35.8 & 30.4 & \\
\hline Dairies & & & 0.70 \\
\hline Never & 5.2 & 3.5 & \\
\hline$<1$ portion/day & 17.9 & 15.1 & \\
\hline$>1$ portion/day & 76.8 & 81.4 & \\
\hline Cheese & & & 0.91 \\
\hline$\leq 1$ portion/day & 58.5 & 59.9 & \\
\hline$\geq 2$ portions/day & 41.5 & 40.1 & \\
\hline Bread & & & 0.87 \\
\hline$<50$ g/day & 35.4 & 37.8 & \\
\hline 50 to $200 \mathrm{~g} /$ day & 60.7 & 58.1 & \\
\hline$>200$ g/day & 3.9 & 4.1 & \\
\hline Dessert & & & 0.03 \\
\hline$\leq 1$ time/week & 31.9 & 37.4 & \\
\hline 2 to 4 times/week & 52.8 & 40.4 & \\
\hline >4 times/week & 15.3 & 22.2 & \\
\hline Added sugar & & & 0.81 \\
\hline$\leq 10$ g/day & 83.4 & 81.4 & \\
\hline$>10 \mathrm{~g} /$ day & 16.6 & 18.6 & \\
\hline
\end{tabular}


Table 4 Univariate and multivariate RRs $(95 \% \mathrm{Cl})$ for quartile 1 of dietary score versus quartiles $2-4$ in AGA versus SGA groups

Quartiles 2-4 ( $\mathrm{n}=\mathbf{3 0 1}$ ) Quartile 1 ( $\mathrm{n}=\mathbf{1 0 0 )} \quad$ Univariate RR (95\% Cl) $\quad$ Multivariate RR $(95 \% \mathrm{Cl})$

\begin{tabular}{lllll}
\hline AGA & 170 & 59 & 1 & 1 \\
Mean (SD) dietary score & $4.5(0.8)$ & $2.6(0.3)$ & & $0.92(0.65$ to 1.30$)$ \\
SGA & 131 & 41 & $0.92(0.65$ to 1.30$)$ & $0.92(0.5)$ \\
Mean (SD) dietary score & $4.3(0.8)$ & $2.5(0.5)$ & &
\end{tabular}

Multivariate analyses adjusted for age and sex.

AGA, appropriate for gestational age; RR, relative risk; SGA, small for gestational age.

the correct consumed portions and usual dietary habits. Besides, it might also be difficult to find differences in scores based on 19 items only. We are also cognisant that it did not evaluate fruit and vegetable intake. However, since the same questionnaire was used for SGA and AGA individuals, this limitation applies to both groups. The restricted items in the questionnaire stem from the fact that fetal programming has been associated with a higher carbohydrate and fat intake, so there was a purpose to target those food groups in the Haguenau cohort. Moreover, there were no data on breast feeding and physical activity, which has been shown to have a positive impact regarding metabolism on children and adults; ${ }^{19}$ we then cannot exclude this potential confounding factor.

We are also aware that the Food Frequency Questionnaire can be systematically erroneous, but no additional data were available regarding dietary intake, so validation with other dietary assessment methods was not possible. Besides, the results of the multivariate analyses and the lack of significance in dietary scores in SGA-born versus AGA-born adults might be explained by the limited sample with available dietary data in this cohort. Additionally, data from the Haguenau cohort has shown that SGA-born versus AGA-born adults were metabolically different and that SGA-born adults have a higher risk of developing the metabolic syndrome versus AGA-born adults (17 out of 734 SGA-born in contrast to 3 out of 886 AGA-born). This difference in the risk of metabolic syndrome was not seen in our subpopulation with available dietary data, especially since we are dealing with a small sample size. Thus, we are cognisant that food preferences may not be as different as in those who were not included in those analyses, which indeed were metabolically different.

The main strengths of the present study include the homogeneous population studied and the high participation rate. Individuals grew up at a time when nutritional conditions were optimal and uniform in the area of Haguenau and were of the same socioeconomic background.

In conclusion, this study provides some evidence of differences in selected food items between adults born SGA and those born AGA. However, no differences were found in the risk of belonging to the lower quartile of adherence to recommendations in SGA-born versus
AGA-born individuals. To the best of our knowledge, this is the first study to compare dietary intakes in adulthood of individuals born either SGA or AGA. These results suggest that parameters associated with fetal programming have a higher role in the development of metabolic syndrome in adulthood rather than dietary intake. Further studies are needed to better understand the impact of dietary intake in participants born SGA.

Author affiliations

${ }^{1}$ INSERM UMS 011, Population-Based Cohorts, France

${ }^{2}$ Nutrition Department, Hôpital Européen Georges-Pompidou, Paris, France

${ }^{3}$ INSERM CIE 05 - Unité d'épidémiologie clinique, Hôpital Robert Debré,

Paris, France

${ }^{4}$ INRA, UMR 1019, Human Nutrition Unit, CRNH Auvergne, Clermont-Ferrand, France

${ }^{5}$ Université d'Auvergne, Clermont Université, 63122 Saint-Genès Champanelle, France

${ }^{6}$ Paris Descartes University, Paris, France

Contributors JM performed statistical analyses and drafted the manuscript. SC contributed to the interpretation of results and revised the manuscript. CC, CLM, JB, MP, FH, MZ, EP-G and BC edited and reviewed the manuscript. All authors read and approved the final manuscript.

Funding This study was funded by the 'Fondation Francophone pour la recherche sur le diabete'.

Competing interests None declared.

Patient consent Obtained.

Ethics approval The ethical committee of the Saint Louis Medical School at the Paris Diderot, University of Paris.

Provenance and peer review Not commissioned; externally peer reviewed.

Data sharing statement No additional data are available.

Open Access This is an Open Access article distributed in accordance with the Creative Commons Attribution Non Commercial (CC BY-NC 4.0) license, which permits others to distribute, remix, adapt, build upon this work noncommercially, and license their derivative works on different terms, provided the original work is properly cited and the use is non-commercial. See: http:// creativecommons.org/licenses/by-nc/4.0/

\section{REFERENCES}

1. Barker DJ. The fetal and infant origins of disease. Eur J Clin Invest 1995;25:457-63.

2. Hales CN, Barker DJ. The thrifty phenotype hypothesis. Br Med Bull 2001;60:5-20.

3. Neel JV. Diabetes mellitus: a "thrifty" genotype rendered detrimental by "progress"? Am J Hum Genet 1962;14:353-62.

4. Jaquet $D$, Deghmoun $S$, Chevenne $D$, et al. Dynamic change in adiposity from fetal to postnatal life is involved in the metabolic 
syndrome associated with reduced fetal growth. Diabetologia 2005;48:849-55.

5. Whincup PH, Kaye SJ, Owen CG, et al. Birth weight and risk of type 2 diabetes: a systematic review. JAMA 2008;300:2886-97.

6. Erhuma A, Bellinger L, Langley-Evans SC, et al. Prenatal exposure to undernutrition and programming of responses to high-fat feeding in the rat. Br J Nutr 2007:98:517-24.

7. Lussana F, Painter RC, Ocke MC, et al. Prenatal exposure to the Dutch famine is associated with a preference for fatty foods and a more atherogenic lipid profile. Am J Clin Nutr 2008;88:1648-52.

8. Matta J, Choleau C, Levy Marchal C, et al. Weight for gestational age and metabolically healthy obesity in adults from the Haguenau cohort. BMJ Open 2016;mu. In Press.

9. Papiernik E, Bouyer J, Dreyfus J, et al. Prevention of preterm births: a perinatal study in Haguenau, France. Pediatrics 1985;76:154-8.

10. Meas T, Deghmoun S, Alberti C, et al. Independent effects of weight gain and fetal programming on metabolic complications in adults born small for gestational age. Diabetologia 2010;53:907-13.

11. Estaquio $\mathrm{C}$, Kesse-Guyot $\mathrm{E}$, Deschamps $\mathrm{V}$, et al. Adherence to the French Programme National Nutrition Santé Guideline Score is associated with better nutrient intake and nutritional status. J Am Diet Assoc 2009;109:1031-41.

12. Hercberg $S$, Chat-Yung S, Chaulia M. The French national nutrition and health program: 2001-2006-2010. Int J Public Health 2008;53:68-77.
13. Kromhout D, Bosschieter EB, de Lezenne Coulander C. The inverse relation between fish consumption and 20-year mortality from coronary heart disease. N Engl J Med 1985;312:1205-9.

14. Barbieri MA, Portella AK, Silveira PP, et al. Severe intrauterine growth restriction is associated with higher spontaneous carbohydrate intake in young women. Pediatr Res 2009;65:215-20.

15. Ayres C, Agranonik M, Portella AK, et al. Intrauterine growth restriction and the fetal programming of the hedonic response to sweet taste in newborn infants. Int J Pediatr 2012;2012:657379.

16. Berridge KC. Measuring hedonic impact in animals and infants: microstructure of affective taste reactivity patterns. Neurosci Biobehav Rev 2000;24:173-98.

17. Stein $A D$, Rundle $A$, Wada N, et al. Associations of gestational exposure to famine with energy balance and macronutrient density of the diet at age 58 years differ according to the reference population used. J Nutr 2009;139:1555-61.

18. Shultis WA, Leary SD, Ness AR, et al. Does birth weight predict childhood diet in the Avon longitudinal study of parents and children? J Epidemiol Community Health 2005; 59:955-60.

19. Victora CG, Horta BL, Loret de Mola C, et al. Association between breastfeeding and intelligence, educational attainment, and income at 30 years of age: a prospective birth cohort study from Brazil. Lancet Glob Health 2015;3:e199-205. 